\title{
Straw Bending and Lodging in Landrace Barley: Finite Element Modelling
}

\author{
Dara Jaff',2* and Michael C. Jarvis ${ }^{2}$
}

${ }^{1}$ Biology Department, College of Education, Salabaddin University, Kirkuk Road, Erbil, Kurdistan Region, Iraq 44001; ${ }^{2}$ Environmental Chemistry, Joseph Black Building, Glasgow University, Glasgow G12 8QQ, Scotland, UK.

\begin{abstract}
Barley genotypes selected by farmers or breeders for dry climates need to cope with wide variation in rainfall from year to year. Vigorous vegetative growth is needed for yield when drought terminates growth early, but this character can lead to lodging in years with above average rainfall. Barley cultivars and landraces bred adapted to these conditions have thinner straw than higher-yielding cultivars adapted to more favourable growing conditions and may lodge in a different way. Using straw dimensions and material properties derived from Kurdish landraces of barley, a finite element model of lodging straw under wind and gravity loading was constructed. Bending moments due to gravity and wind were explicitly calculated. For the thin-strawed landrace phenotypes, as lodging progressed, gravity became the dominant influence. The model was used to prioritise different straw parameters that influence lodging. Increasing straw diameter was the most promising way to improve resistance to lodging, since diameter showed more variation than straw length and gave greater gains in stiffness than increasing the longitudinal modulus of the straw material.

Received | March 05, 2020; Accepted | October 25, 2020; Published | May 23, 2021

*Correspondence | Dara Jaff, Biology Department, College of Education, Salahaddin University, Kirkuk Road, Erbil, Kurdistan Region, Iraq 44001; Email: d95uk@yahoo.co.uk

Citation | Jaff, D. and M.C. Jarvis. 2021. Straw bending and lodging in landrace barley: finite element modelling. Sarhad Journal of Agriculture, 37(2): 555-563.

DOI | https://dx.doi.org/10.17582/journal.sja/2021/37.2.555.563

Keywords | Farm-saved seed, Biomechanics, Lodging, Moisture content, Stiffness
\end{abstract}

\section{Introduction}

$\mathrm{L}$ odging in cereals is a major economic problem worldwide due to direct loss of yield, increased costs of harvesting and fungal infection of the slowdrying lodged crop (Berry et al., 2004; von Korff et al., 2008). In rainfed subsistence agriculture, droughtresistant barley cultivars and landraces are capable of producing a crop on well under $300 \mathrm{~mm}$ of rain (Varshney et al., 2012). In excessively dry years when there is little grain yield the straw is often grazed or harvested for fodder and may play a vital economic role in keeping livestock alive (Goodchild, 1997). These conditions demand rapid vegetative growth in the short period while soil moisture is adequate prior to terminal summer drought. Genotypes adapted to these conditions tend to have thin, flexible straw. In a wet year, however, these characteristics lead to excessive plant height and problems with lodging (Goodchild, 1997).

Lodging mechanisms have been reviewed by Berry et al. (2004). Lodging can occur by displacement of the root system and the soil surrounding it; by buckling (folding) (Cui and Shen, 2011; Spatz and Speck, 1994) or more rarely fracture of the hollow straw (Tan et al., 2015); or by a combination of these mechanisms (Farquhar et al., 2002; Niklas, 1998). Lodging in barley is more complex than in wheat and some other cereals, because barley stems are relatively 
flexible and can fail at any point along their length (Berry et al., 2006). Field observations on the thinstrawed drought-resistant genotypes grown in arid areas (Jaff, 2019) show that their straw is so flexible that lodging can occur without fracture or buckling, as the stems arched elastically until the spike touched the ground, and was held down by gravity only.

Lodging in barley has been modelled by various analytical and finite element approaches (Berry et al., 2004; Cui and Shen, 2011; Baker et al., 2014; Dunn and Briggs, 1989; Lebliqc et al., 2016; Neenan and Spencer-Smith, 1975). Recently dynamic models, matching wind turbulence to the oscillation of the shoot (Bruchert et al., 2003; Gardiner et al., 2016) have proved useful for predicting the prevalence of lodging depending on weather (Berry et al., 2006; Baker et al., 2014) and for assessing the relative importance of straw, root and soil characteristics. The possibility of a different form of lodging in extremely drought-resistant barley suggests that models with a different structure, allowing the direct effect of gravity to be assessed separately from the effect of wind forces, might be advantageous. In a dynamic model this would become computationally difficult when lodging approaches the critical point where gravity alone prevents the straw from recovering elastically, as its motion will then be increasingly non-harmonic: That is, the swaying shoot will not oscillate symmetrically in response to a gust of wind. An additional advantage would be the possibility to assess the gravity contribution of changes in moisture content prior to harvest.

Finite element models, based on relating local force to the deformation in each short segment of the straw, have been used to simulate the bending of barley straw and offer more flexibility than analytical models in which the whole length of the straw is modelled at once (Cui and Shen, 2011; Lebliqc et al., 2016). Here we describe a simple form of non-dynamic finite element model simulating the lodging of a set of drought-resistant barley landraces described in an accompanying paper (Jaff, 2019) under the combined, but explicitly separable, influences of wind and gravity. It was not an objective to predict absolute levels of lodging under any particular combination of weather conditions. Instead the focus was on the relative susceptibility of different barley phenotypes to lodging. The practical objective was to prioritise straw characteristics that could be used to improve lodging resistance, if possible without leading to reductions in the feeding value of the straw (Goodchild, 1997). It was also the intention that the model would not require specialised finite element modelling software or skills, which might be inaccessible in the regions concerned. Instead the models were simply implemented in Microsoft Excel.

\section{Materials and Methods}

The input dimensions, mass and material characteristics derive from Jaff (unpublished).and relate to barley straw with much smaller diameter and lighter head weight than is normal in high-yielding commercial cultivars adapted to conditions of high fertility and ample water.

Each internode was divided into either 5 or 10 longitudinal segments, depending on its length. Each segment was treated as a tube bending under the influence of wind and the force of gravity on the parts of the shoot distal to its basal end. The input data were the length, outside diameter, culm wall thickness (i.e. the mean of combined thickness of the epidermis and sclerenchyma (Cenci et al., 1984)), dry mass and moisture content (10\% unless otherwise stated) of each segment and the mean longitudinal modulus of the cell-wall material i.e. the stiffness calculated using the cross-sectional area of solid material; the mass, width and length of the spike, including the length of the awns; the wind speed at the height of the segment, using a simple exponential model for the vertical wind gradient within the crop; a constant drag factor of 0.4 for both spike and straw (Baker et al., 2014); and the torque constant for displacing the root system through a given angle. Only the top internode was modelled as tapered. The analysis was done in three operations.

1. For each segment an arbitrary bending angle was chosen, together with an arbitrary angle for root lodging. These angles allowed a starting geometry for the whole plant to be constructed

2. The forces exerted by wind and gravity on each segment of the straw and on the spike were then calculated, and hence the bending moment (torque) at the base of each segment due to wind and gravity forces acting on all segments distal to it, including itself and the spike. The bending stiffness of each segment was calculated from its dimensions and the longitudinal modulus of its cell-wall material. A predicted value for the angle 
through which each segment bends was calculated from its stiffness and the bending moment at its base, based on the starting geometry of the shoot.

3. The bending angles for all segments of the straw were then adjusted simultaneously to minimise the difference between the starting (step 1) and predicted (step 2) geometries. The iterative minimisation procedure was numerically challenging because each change in any starting angle affected the forces acting on all the other segments. Two approaches were used: Leastsquares minimisation of the differences between the geometrical and predicted mechanical segmental bending angles using the Solver addin function in Microsoft Excel, and iterative averaging of geometrical and predicted mechanical segmental bending angles. In most circumstances these two approaches led to identical solutions. However, each method led to unstable solutions in some circumstances, particularly when the straw was almost straight and upright or when segmental bending angles became large. In these circumstances the solutions from the iterative bending approach tended to oscillate but this problem was minimised by extending the number of iterations to 100 and averaging the output from the last 20 iterations. The data shown in Figures 1-5 were derived by the iterative averaging procedure.

The equations on which the model was based are shown in Table 1 . The input parameters are shown in Table 2.

As with other models of lodging, a number of simplifying physical approximations were assumed. The anatomical heterogeneity of the culm wall was ignored. The data and images in (Cenci et al., 1984) suggest that approximately half of the mass and threequarters of the stiffness of the culm wall reside in the epidermis and the sclerenchyma ring, where the cells are particularly thick-walled. The densities and longitudinal moduli of these tissues, the parenchyma and the vascular bundles were all effectively combined into single density and modulus values for the whole culm wall. Also, the landrace barley populations from which the starting parameters were standardised had rather long, clasping leaf sheaths Jaff, unpublished, the contribution of which to the mass, wind resistance and stiffness of the stem were ignored. These simplifications were due to the amount of data available on culm anatomical parameters, not limitations of the model, which could readily be adapted for more complex parameter sets if required. In the form reported here the model already describes the anatomy of barley straw in considerably more detail than is possible with existing analytical models.

The starting point for optimisation of the modelled straw geometry was vertical with the topmost two segments of the top internode bent slightly downwind, directing the minimisation towards the downwind side. To prevent mathematical complications the modelled lodging was stopped when the spike touched the ground. In practice the plant will subsequently fall further with the upper part of the straw becoming concave, but this was not included in the model.

\section{Results and Discussion}

The aim of the finite element modelling exercise was to compare the relative effect of changing a number of straw parameters in minimising the extent of lodging in strong winds. It was not an aim to predict the extent of lodging quantitatively at any particular wind speed, which would have required a dynamic approach to the lodging phenomenon (Baker et al., 2014) and would have depended heavily on a statistical approach to the turbulent behaviour of the wind (Finnigan, 1979). The dimensions for each comparison corresponded approximately to the range of variation within the four landrace populations measured by Jaff (2019).

Figure 1 shows the progressively increasing modelled severity of lodging under increasing wind speeds up to $25 \mathrm{~m} \mathrm{~s}^{-1}$. The relative contributions of (a) the direct effect of wind, and (b) the effect of gravity, to the torque (bending moment) exerted at any point on the straw, vary according to the wind speed, but the effect of gravity is always large. That is, much of the bending moment is due to the weight of the spike and to the straw's own weight, as soon as the straw is displaced from vertical (Crook and Ennos, 1995). The greatest total bending moment is in general near the base of the straw, but the finely tapered top internode bends considerably, allowing the head to droop. Positive torque bends the shoot to the right in the diagram. With this convention, wind torque exerted on parts of the straw higher than the drooping head is negative because the spike is then blown upwards towards a horizontal position in strong winds. In principle bending of the straw is elastic (reversible), 
Table 1: Equations for shoot geometry and mechanics.

Properties of each internode segment

Outer radius $(\mathrm{m})=r$

Internode wall thickness $(\mathrm{m})=t$

Inner radius $(\mathrm{m})=r-t$

Length $(\mathrm{m})=L$

Internode wall density $=500 \mathrm{Kg} / \mathrm{m}^{3}$

mass $(\mathrm{Kg})=M=500 L \pi\left(r^{2}-(r-t)^{2}\right)$

Second moment of area $\left.I\left(\mathrm{~m}^{4}\right)=\pi(2 r)^{4}-(2(r-t))^{4}\right) / 64$

Longitudinal bending modulus $\left(\mathrm{Nm}^{2}\right)=E$

Stem geometry

Root lodging angle (radians) $=\theta_{\mathrm{R}}$

Angle through which segment $i$ is bent (radians) $=\theta_{\mathrm{i}}$ (geom)

Angle from vertical $V_{\mathrm{i}}$ at top of segment $i$ (radians) $)=\theta_{\mathrm{R}}+\theta\left(0\right.$ to i) $\theta_{\mathrm{i}}$

Lateral position $X_{\mathrm{i}}$ at top of segment $i(\mathrm{~m})=X_{\mathrm{i}-1}+L_{\mathrm{i}} \sin V_{\mathrm{i}}$

Vertical position $H_{\mathrm{i}}$ at top of segment $i(\mathrm{~m})=H_{\mathrm{i}-1}+L_{\mathrm{i}} \cos V_{\mathrm{i}}$

Radius of curvature $R_{\mathrm{i}}(\mathrm{m})=L_{\mathrm{i}} / \theta_{\mathrm{i}}$

Straight length of segment $(\mathrm{m})=2 R_{\mathrm{i}} \sin \left(\theta_{\mathrm{i}} / 2\right)$

Wind and gravitational forces

Gravity force on internode $(\mathrm{N})=9.8 \Sigma M_{\mathrm{i}}$ (assumed to act vertically at centre of internode)

Gravity total torque to segment base $(\mathrm{Nm})=9.8 \Sigma X M$ summed over spike and all internodes distal to internode considered

Wind speed above canopy $\left(\mathrm{m} \mathrm{s}^{-1}\right)=v$

Wind speed $v_{\mathrm{H}}\left(\mathrm{m} \mathrm{s}^{-1}\right)$ at height $H=v(\exp (H)-1) /(\exp ($ canopy height $)-1)$

Area of internode projected to wind $\left(\mathrm{m}^{2}\right)=A=2 r$ abs $\left(H_{\max }-H_{0}\right)$

Wind force on internode $(\mathrm{N})=W=A$ (drag factor) $v_{\mathrm{H}}^{2} / 2$

Wind torque at segment base $(\mathrm{Nm})=\Sigma H W$ summed over spike and all internodes distal to internode considered

Total torque at segment base $(\mathrm{Nm})=$ Wind torque + gravitational torque .

Total force normal to segment tip $(\mathrm{N})=$ Total torque at segment base/straight length of segment

Note that the wind and gravity torques are positive when bending the straw clockwise. The wind torque is negative when acting on a segment further above the ground than a drooping head.

\section{Mechanical outcome}

Root lodging angle (mech) (radians) $=$ (Total torque at base of shoot) (Root lodging constant)

Angle $\theta_{\mathrm{i}}$ (mech) through which each segment $i$ is bent (radians) $=2 \arctan \left(\right.$ Total force normal to segment base (straight length) ${ }^{2} /$ $(3 E I))$

The fitting process is to adjust $\theta_{\mathrm{i}}$ (geom) simultaneously for all internode segments $i$ until $\theta_{\mathrm{i}}$ (geom) and $\theta_{\mathrm{i}}$ (mech) are matched.

Table 2: Standard input parameters.

$\begin{array}{lllll}\text { Internode no from base } & \mathbf{1} & \mathbf{2} & \mathbf{3} & \mathbf{4} \\ \text { No of segments } & \mathbf{5} & \mathbf{5} & \mathbf{5} & \mathbf{1 0} \\ \text { Internode length }(\mathrm{m}) & 0.056 & 0.122 & 0.165 & 0.242 \\ \text { Outer radius }(\mathrm{m}) & 0.00076 & 0.00086 & 0.0008 & 0.00080 \text { to } 0.00025 \\ \text { Wall thickness }(\mathrm{m}) & 0.00024 & 0.00027 & 0.0003 & 0.00030 \text { to } 0.00010 \\ \text { Culm wall modulus }(\mathrm{GPa}) & 10 & 10 & 10 & 5 \\ \text { Spike length }(\mathrm{m}) & 0.056 & & & \\ \text { Spike width }(\mathrm{m}) & 0.006 & & & \\ \text { Spike mass }(\mathrm{Kg}) & 0.002 & & & \\ \text { Culm wall density }\left(\mathrm{Kg} / \mathrm{m}^{3}\right) & 500 & & & \\ \text { Drag factor } & 0.4 & & & \\ \text { root lodging constant }\left(\text { radians } \mathrm{N}^{-1} \mathrm{~m}^{-1}\right) & 10 & & & \end{array}$

June 2021 | Volume 37 | Issue 2 | Page 558 


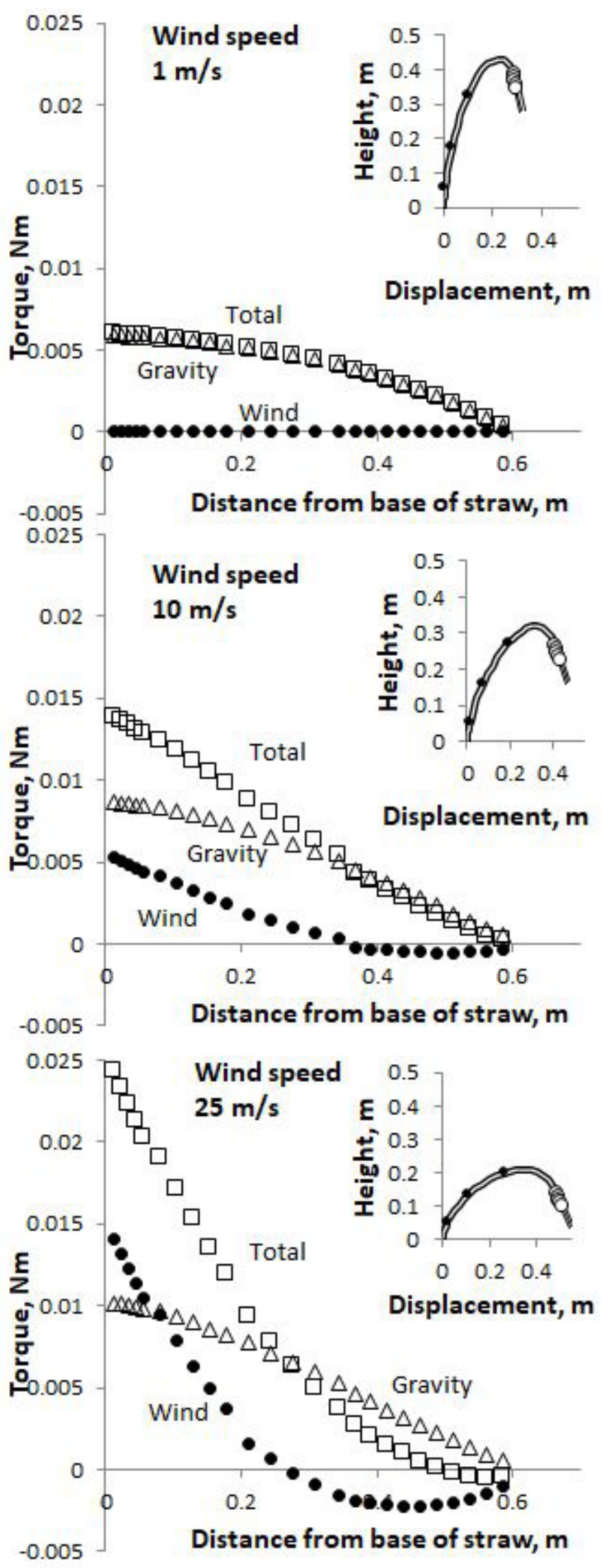

Figure 1: Modelled effect of wind strength on lodging and the relative contributions of wind (horizontal) and gravity (vertical) to the torque bending the stem at each point on its length measured along the curve from base to tip. Inset: plant geometry at each wind strength. its original vertical posture when the wind force is removed: If the head is displaced far enough laterally the force of gravity alone will be sufficient to keep the straw curved over. This is particularly the case if there is significant displacement of the root system, which may be assumed to be partly irreversible (Crook and Ennos, 1995).

Cereal straw commonly fails through folding because it is not transversely stiff enough to maintain its circular cross-section when bent. This form of failure is called Brasier buckling and it occurs at a torque (force $\mathrm{x}$ leverage) that is called the critical bending moment. Using an estimated value of $2 \mathrm{GPa}$ for the tangential modulus of the culm walls, the modelled critical bending moment for the onset of Brasier buckling (Cui and Shen, 2011; Niklas, 1998) is approximately $0.2 \mathrm{Nm}$ up to the base of the top internode, decreasing to $0.008 \mathrm{Nm}$ at the tip. Comparing with the bending moments in Figure 1, there is therefore a safety factor of around an order of magnitude for this form of failure. However, greater bending moments than predicted by the model would be expected under the dynamic conditions of a sudden gust coincidentally matching the harmonic frequency of the shoot (Baker et al., 2014).

It might be expected that barley crops would become more susceptible to lodging towards harvest as grain filling increased the weight of the head. At $15 \mathrm{~m}$ $\mathrm{s}^{-1}$ wind speed the modelled overall lodging angle, defined as the angle from vertical of a line from base to tip of straw, increased from $55^{\circ}$ to $62^{\circ}$ when the head mass was increased from $1 \mathrm{~g}$ to $2 \mathrm{~g}$. However, increasing the moisture content of both head and straw from $10 \%$ to $110 \%$, while keeping the head dry mass at $1 \mathrm{~g}$, increased the modelled overall lodging angle to $63^{\circ}$. Thus, the predicted effect of increasing head weight is counteracted by reduced weight of moisture in both spike and straw as the crop dries out under conditions of terminal drought. This does not take into account the expected increase in the stiffness of the straw cell-wall material when dry (Tavakoli et al., 2009), nor the increased soil shear strength when the soil moisture content is low (Martinez-Vazquez, 2016). Also, during heavy rain additional water may cling on the surface of the plant and between the leaf sheath and the internode. Thus, the model predictions are consistent with the greatest susceptibility to lodging being several weeks before harvest when both plant and soil have relatively high moisture content, but this is naturally dependent on rain and its timing 
during the pre-harvest period.

Figure 2 shows that resistance to lodging can potentially be greatly improved by increasing the diameter of the straw, while keeping the taper and culm wall thickness proportionate. The maximum factor of two by which the diameter was increased is equivalent to the variability in mean observed straw diameter within and between the landrace populations and is predicted to give an eightfold increase in bending stiffness. The increased stiffness of the straw at larger diameters led to an increase in the root lodging angle, from $9^{0}$ to $18^{0}$ over the diameter range shown in Figure 2.

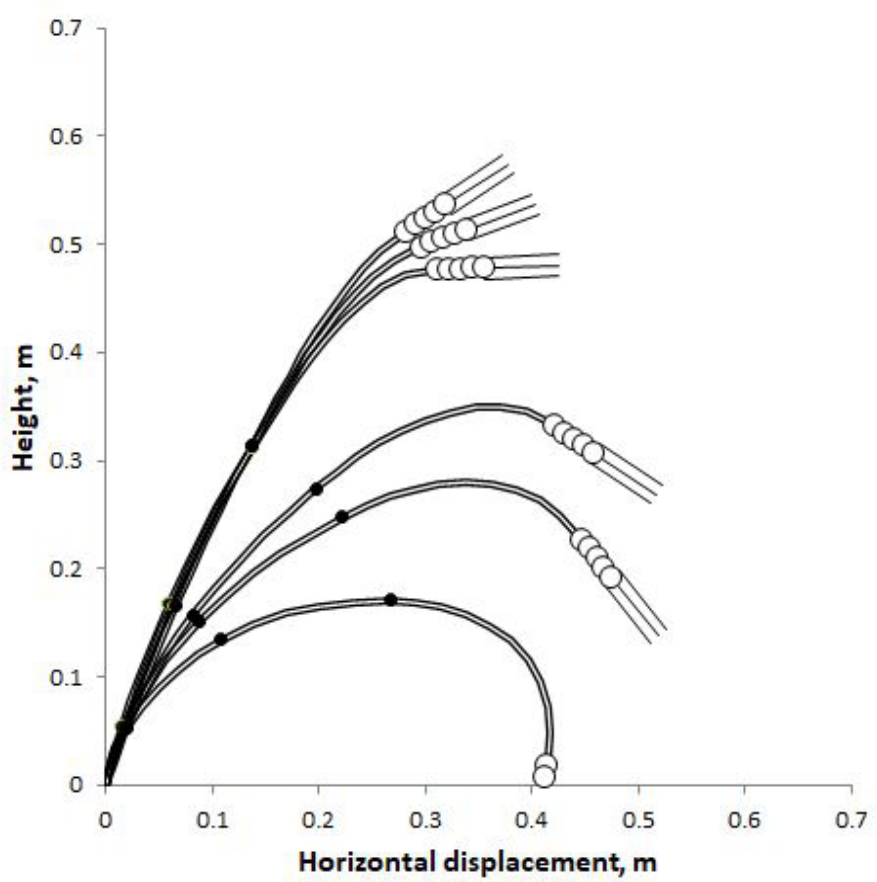

Figure 2: Modelled effect of straw diameter on lodging at $15 \mathrm{~m} \mathrm{~s}^{-1}$ wind speed. Maximum diameter (internode 2), top to bottom $(\mathrm{m})$ : $.00309,0.00275,0.00240,0.00206,0.00172,0.00137$. Diameters and wall thicknesses of other internodes were held in constant ratio to internode 2.

With the largest straw diameters modelled the spike was more upright, leading to a considerable increase in its wind resistance despite the drooping habit of the barley spike (Figure 2). At the largest diameters, comparable with those encountered in commercial barley cultivars bred for temperate climates, increases in straw diameter made little further difference to the bending of the straw at the value of root stability used here and the principal effect of wind was to cause root lodging.

Increasing the longitudinal modulus of the straw cell walls by a factor of two had a smaller modelled effect than increasing the straw diameter by the same factor (Figure 3). As with diameter, a factor of two variation in modulus corresponds approximately to the variability observed in the field.

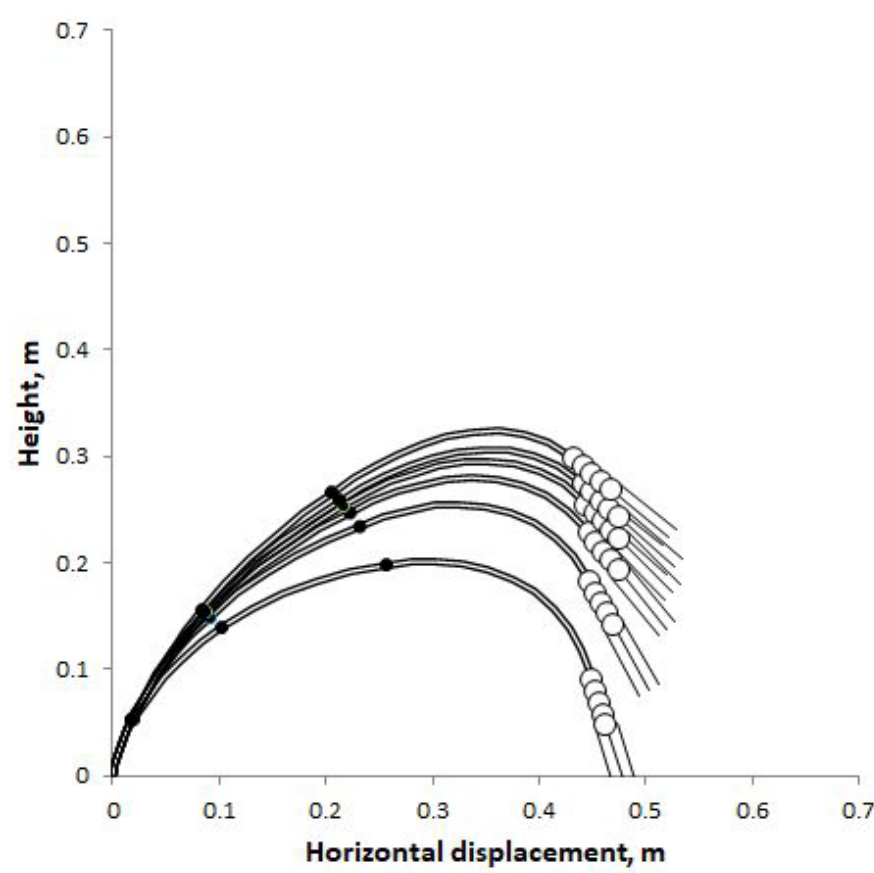

Figure 3: Modelled effect of mean longitudinal modulus of the culm wall material on lodging at $15 \mathrm{~m} \mathrm{~m} \mathrm{~s}^{-1}$ wind speed. Modulus for the three lower internodes, top to bottom (GPa): 16, 14, 12, 10, 8, 6. The top internode had half the modulus of the three lower internodes.

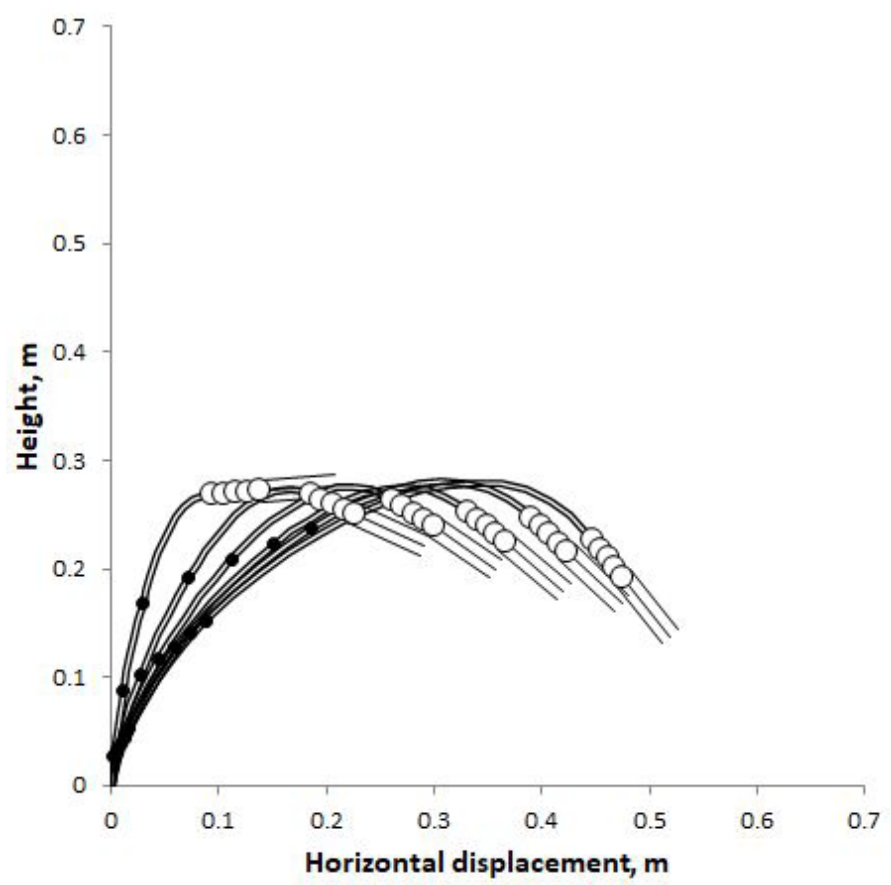

Figure 4: Modelled effect of straw length on lodging at $15 \mathrm{~m} \mathrm{~s}^{-1}$ wind speed. Erect plant heights $(\mathrm{m})$, right to left: $0.64,0.58,0.52$, $0.47,0.41,0.35$.

Halving the length of the straw (Figure 4) gave a similar reduction in lodging when compared with doubling the straw diameter. The observed range of variation in straw length between phenotypes was 
considerably less than twofold, however. The main effect on straw length in these landraces is expected to be between dry and wet years (Goodchild, 1997).

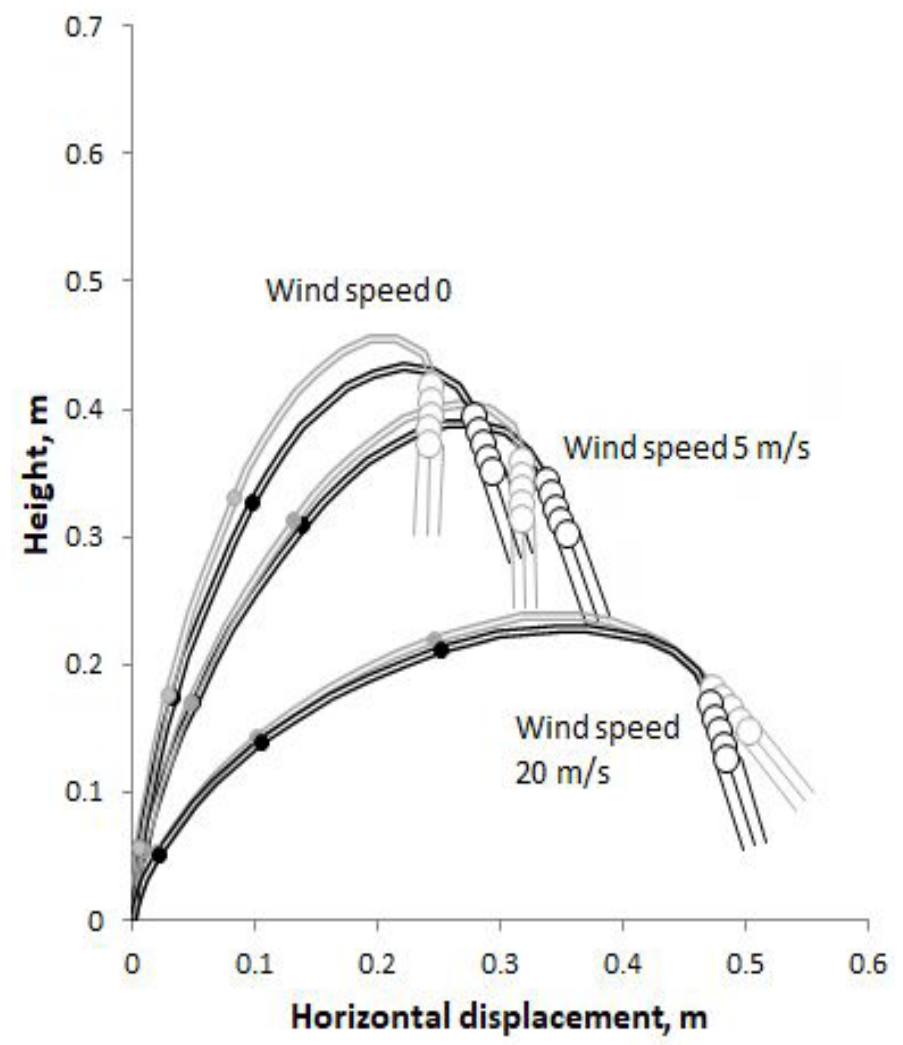

Figure 5: Modelled effect of a permanent bend (set) at the top of the apical internode, at wind speeds of 0, 5 and $20 \mathrm{~m} \mathrm{~s}^{-1}$. No permanent set: grey. Permanent set: black.

In most barley populations there is a small permanent bend (set) in the top internode and the rachis of the spike, keeping the spike approximately horizontal or somewhat drooping when there is no wind and reducing the projected area of the spike at low wind strengths while allowing the glumes and awns to intercept sunlight well. However, reduced wind resistance is accompanied by increased gravitational torque. Figure 5 shows that when the top internode was as thin and strongly tapered as assumed here, a permanent bend did not make a large difference at moderate wind strengths because, even if the top internode was initially straight, it took on a substantial bend under the influence of gravity. It is assumed that the permanent bend in the top internode is indeed aligned with the current wind direction. If not, as may happen in the gusts of variable direction in thundery weather, twisting stresses on the straw will result.

The modelling exercise showed that the greatest potential gain in straw stiffness, utilising the phenotypic variation in the landraces studied, would be obtained by increasing the straw diameter and by reducing the plant height, as observed for barley adapted to temperate conditions (Berry et al., 2006). All strategies for increasing straw stiffness involve trade-offs. If straw diameter is increased there will be a proportionate increase in straw yield, which may be accompanied by decreased yield of grain to an extent depending on the relative timing of straw growth and grain set (White, 1995). The relative value of grain and straw to the farmer will then be an input into the selection strategy (Goodchild, 1997). Reducing plant height should achieve a reduction in lodging with approximately the opposite effect on grain yield.

Potential reductions in lodging resulting from stiffer internode walls were relatively small. The mean stiffness of the internode wall can be augmented either anatomically or at the level of cell-wall structure. Anatomically, the stiffness of the internode can be increased by increasing the proportion of its thickness occupied by sclerenchyma tissue or increasing the thickness of the sclerenchyma cell walls (Neenen and Spencer-Smith, 1975; Cenci et al., 1984). Sclerenchyma cell-wall synthesis is under the control of transcription factors (Rao and Dixon, 2018) and its impairment leads to correlated loss of mechanical performance and gain in feeding value (Sato et al., 2018). At the cell-wall level, experience with softwoods suggests that much developmental and heritable variation in stiffness results from varying cellulose orientation (microfibril angle) (Barnett and Bonham, 2004). Microfibril angle affects longitudinal and tangential stiffness in opposite directions. Tangential stiffness in tubular structures is a factor in ovalisation and susceptibility to buckling (Spatz and Speck, 1994). Thus longitudinally stiffer straw derived by decreasing the microfibril angle would be expected to have a somewhat reduced safety factor towards buckling. Changing the microfibril angle makes no difference to chemical composition nor, presumably, digestibility.

These trade-offs are representative of a number of interactions between heritable factors affecting lodging and the feeding value of straw, which deserve to be considered during the search for genes that can be exploited when breeding barley. Bringing together genomics (Mascher et al., 2017), exploitable genetic control of straw properties other than length (Berry and Berry, 2015), and improved understanding of the relationship between cell-wall structure and mechanical properties (Cosgrove and Jarvis, 2012) will be central to future developments in this area. 


\section{Conclusions and Recommendations}

1. Landrace barley populations from Kurdistan had very thin straw which made them susceptible to an unusual form of lodging in which the straw curves over under the weight of the head, without fracture. Finite element models of this type of lodging allowed the contributions of wind and gravity to be separated.

2. The models allowed the prediction that increasing straw diameter and reducing straw length were likely to be the most promising strategies for reducing lodging.

3. Smaller gains in resistance to lodging could be expected from thicker or stiffer cell walls.

4. The drooping habit of barley heads made only a small difference to predicted susceptibility to lodging.

\section{Acknowledgements}

We thank Drs S. Ceccarelli and S. Grando (ICARDA) for useful discussions on breeding barley for dryland conditions.

\section{Novelty Statement}

Thin-strawed landrace barley was susceptible to lodging without fracture. Finite element models allowed the contributions of wind and gravity to be separated. Increasing straw diameter and reducing straw length were the most promising strategies for reducing lodging. Smaller gains came from thicker or stiffer cell walls. The drooping habit of barley heads made little difference to lodging.

\section{Author's Contribution}

Dara Jaff DJ provided the input data and Michael C. Jarvis developed the finite element model. Both authors wrote the paper.

\section{Conflict of interest}

The authors have declared no conflict of interest.

\section{References}

Baker, C.J., M. Sterling and P. Berry. 2014. A generalised model of crop lodging. J. Theor. Biol., 363: 1-12. https://doi.org/10.1016/j. jtbi.2014.07.032
Barnett, J.R. and V.A. Bonham. 2004. Cellulose microfibril angle in the cell wall of wood fibres. Biol. Rev., 79: 461-472. https://doi. org/10.1017/S1464793103006377

Berry, P.M. and S.T. Berry. 2015. Understanding the genetic control of lodging-associated plant characters in winter wheat (Triticum aestivum L.). Euphytica, 205: 671-689. https://doi. org/10.1007/s10681-015-1387-2

Berry, P.M., M. Sterling and S.J. Mooney. 2006. Development of a model of lodging for barley. J. Agron. Crop Sci., 192: 151-158. https://doi. org/10.1111/j.1439-037X.2006.00194.x

Berry, P.M., M. Sterling, J.H. Spink, C.J. Baker, R. Sylvester-Bradley, S.J. Mooney, A.R. Tams and A.R. Ennos. 2004. Understanding and reducing lodging in cereals. Adv. Agron., 84: 217-271. https://doi.org/10.1016/S00652113(04)84005-7

Bruchert, F., O. Speck and H.C. Spatz. 2003. Oscillations of plants' stems and their damping: Theory and experimentation. Philos. T. R. Soc. B., 358: 1487-1492. https://doi.org/10.1098/ rstb.2003.1348

Cenci, C.A., S. Grando and S. Ceccarelli. 1984. Culm anatomy in barley (Hordeum vulgare). Can. J. Bot., 62: 2023-2027. https://doi. org/10.1139/b84-275

Cosgrove, D.J. and M.C. Jarvis. 2012. Comparative structure and biomechanics of plant primary and secondary cell walls. Front. Plant Sci., 3: 6-14. https://doi.org/10.3389/fpls.2012.00204

Crook, M.J. and A.R. Ennos, 1995. The effect of nitrogen and growth regulators on stem and root characteristics associated with lodging in 2 cultivars of winter wheat. J. Exp. Bot., 46: 931938. https://doi.org/10.1093/jxb/46.8.931

Cui, H.-L. and H.-S Shen. 2011. Modelling and simulation of buckling and postbuckling of plant stems under combined loading conditions. Int. J. Appl. Mech., 3: 119-130. https://doi. org/10.1142/S1758825111000907

Dunn, G.J. and K.G. Briggs. 1989. Variation in culm anatomy among barley cultivars differing in lodging resistance. Can. J. Bot., 67: 18381843. https://doi.org/10.1139/b89-232

Farquhar, T., J. Zhou and W.H. Wood. 2002. Competing effects of buckling and anchorage strength on optimal wheat stalk geometry. J. Biomech. Eng-TA SME., 124: 441-449. https://doi.org/10.1115/1.1488934 
Finnigan, J.J., 1979. Turbulence in waving wheat. I. Mean statistics and Honami. Bound. Layer Meteorol., 16: 181-211. https://doi. org/10.1007/BF03335366

Gardiner, B., P. Berry and B. Moulia. 2016. Review: Wind impacts on plant growth, mechanics and damage. Plant Sci., 245: 94-118. https://doi. org/10.1016/j.plantsci.2016.01.006

Goodchild, A.V., 1997. Effects of rainfall and temperature on the feeding value of barley straw in a semi-arid Mediterranean environment. J. Agric. Sci., 129: 353-366. https://doi. org/10.1017/S002185969700470X

Jaff, D.M.A., 2019. Straw stiffness in landraces of two-row barley (Hordeum vulgare L.) Iraqi J. Agric. Sci. 50: 1597-1604. https://doi. org/10.36103/ijas.v50i6

Leblicq, T., B. Smeets, S. Vanmaercke, H. Ramon and W. Saeys.2016. A discrete element approach for modelling bendable crop stems. Comput. Electron. Agric., 124: 141-149. https://doi. org/10.1016/j.compag.2016.03.022

Martinez-Vazquez, P., 2016. Crop lodging induced by wind and rain. Agric. Forest Meteorol., 228: 265-275. https://doi.org/10.1016/j. agrformet.2016.07.003

Mascher, M., H. Gundlach, A. Himmelbach, S. Beier, S.O. Twardziok, T. Wicker T., V. Radchuk, C. Dockter, P.E. Hedley, J. Russell, M. Bayer, L. Ramsay, H. Liu, G. Haberer, X.Q. Zhang, Q. Zhang, R.A. Barrero, L. Li, S. Taudien, M. Groth, M. Felder, A. Hastie, H. Šimková, H. Staňková, J. Vrána, S. Chan, M. Muñoz-Amatriaín, R. Ounit, S. Wanamaker, D. Bolser, C. Colmsee, T. Schmutzer, L. Aliyeva-Schnorr, S. Grasso, J. Tanskanen, A. Chailyan, D. Sampath, D. Heavens, L. Clissold, S. Cao, B. Chapman, F. Dai, Y. Han, H. Li, X. Li, C. Lin, J. K. McCooke, C. Tan, P. Wang, S. Wang, S. Yin, G. Zhou, J.A. Poland, M.I. Bellgard, L. Borisjuk, A. Houben, J. Doležel, S. Ayling, S. Lonardi, P. Kersey, P. Langridge, G.J. Muehlbauer, M.D. Clark, M. Caccamo, A.H. Schulman, K.F.X. Mayer, M. Platzer, T.J. Close, U. Scholz, M. Hansson, G. Zhang, I. Braumann, M. Spannagl, C. Li, R. Waugh and N. Stein. 2017. A chromosome conformation capture ordered sequence of the barley genome. Nature, 544: 426-435.
Neenan, M. and J.L. Spencer-Smith. 1975. Analysis of problem of lodging with particular reference to wheat and barley. J. Agric. Sci., 85: 495-507. https://doi.org/10.1017/S0021859600062377

Niklas, K.J., 1998. Modes of mechanical failure of hollow, septate stems. Ann. Bot., 81: 11-21. https://doi.org/10.1006/anbo.1997.0505

Rao, X.L. and R.A. Dixon. 2018. Current models for transcriptional regulation of secondary cell wall biosynthesis in grasses. Front. Plant Sci., 9: 399. https://doi.org/10.3389/fpls.2018.00399

Sato, H., S. Sakamoto, N. Mitsuda, M. OhmeTakagi and T. Takamizo. 2018. Improvement of cell wall digestibility in tall fescue by Oryza sativa Secondary Wall NAC Domain Protein 2 chimeric repressor. Mol. Breed., 38: 36. https:// doi.org/10.1007/s11032-018-0796-z

Spatz, H.C. and T. Speck. 1994. Local buckling and other modes of failure in hollow plant stems. Biomimetics, 2: 149-173.

Tan, H.T., N.J. Shirley, R.R. Singh, M. Henderson, K.S. Dhugga, G.M. Mayo G.M. G.B. Fincher and R.A. Burton. 2015. Powerful regulatory systems and post-transcriptional gene silencing resist increases in cellulose content in cell walls of barley. BMC Plant Biol., 15: 62. https://doi. org/10.1186/s12870-015-0448-y

Tavakoli, H., S.S. Mohtasebi and A. Jafari. 2009. Physical and mechanical properties of wheat straw as influenced by moisture content. Int. Agrophys., 23: 175-181.

Varshney, R.K., M.J. Paulo, S. Grando, F.A. van Eeuwijk, L.C.P. Keizer, P. Guo, S. Ceccarelli, A. Kilian, M. Baum and A. Graner. 2012. Genome wide association analyses for drought tolerance related traits in barley (Hordeum vulgare L.). Field Crops Res., 126: 171-180. https://doi. org/10.1016/j.fcr.2011.10.008

von Korff, M., S. Grando, A. Del Greco, D. This, M. Baum and S. Ceccarelli, 2008. Quantitative trait loci associated with adaptation to Mediterranean dryland conditions in barley. Theor. Appl. Genet., 117: 653-669. https://doi. org/10.1007/s00122-008-0787-2

White, E.M., 1995. Effects of management and development on stem characteristics related to lodging in winter barley. Eur. J. Agron., 4: 327-334. https://doi.org/10.1016/S11610301(14)80033-6 